
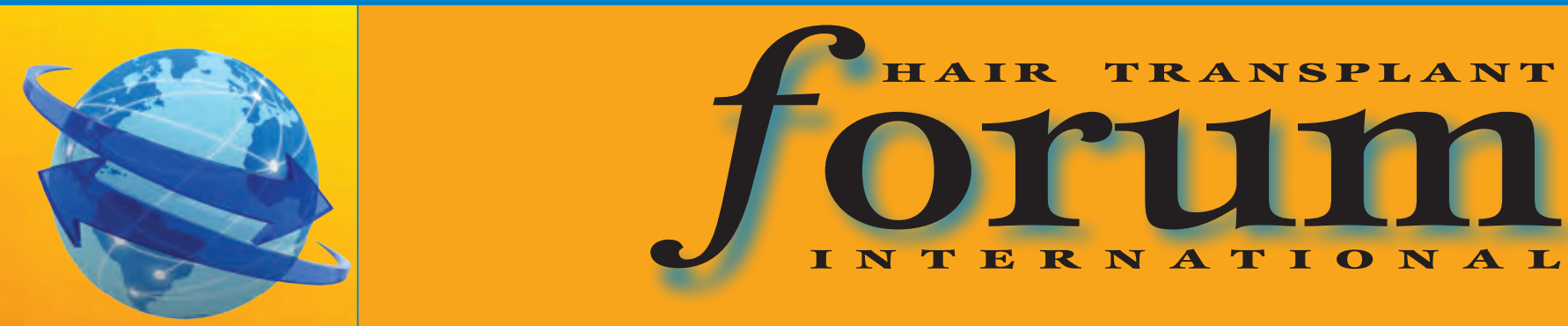

Volume 23, Number 6 • November/December 2013

Inside this issue

President's Message

Co-editors' Messages Notes from the Editor Emeritus: Richard C. Shiell, MBBS.

Facial aspect ratio and the split face photo.

How to use the Laxometer.

Controversies...

FUE Committee: Standardization of the terminology used in

FUE: part II....

Message from the 2014 ASM

Program Chair

Hyaluronidase in hair

transplantation...

Practice Census finds robust growth in hair restoration surgery over the years.

Hair's the Question

Cyberspace Chat:

When finasteride suddenly stops

working-is it counterfeit? ...

Review of the Literature.

Codes of Conduct and

Professional Standards for

Hair Transplant Surgeon

members of the BAHRS

Letters to the Editors

Meetings \& Studies:

Review of the Beautiful Brows

Workshop

ISHRS Annual Giving Fund

2013 Year-End Report.

Surgical Assistants Corner: Hair transplant post-op procedures and products..

Classifieds

\title{
Hairline evolution as simple as ABC/123
}

\author{
William R. Rassman, MD Los Angeles, California, USA; Jae P. Pak, MD Los Angeles, California, USA; \\ Jino Kim, MD Seoul, South Korea wrassman@newhair.com
}

Hairlines show a migration from a basic concave shape at a well-defined anatomical position in early childhood to significantly different shapes and positions as an individual ages. For understanding the focus of this paper, you should not focus on traditional patterns of hair loss as defined by Norwood and Ludwig, although Ludwig showed hair in the frontal hairline zone when significant female balding was present. ${ }^{1,2}$ Hair loss will not be addressed, but rather the normal evolution of a hairline in non-balding and balding people will be covered. In addition, the changes in the hairlines that are discussed here are not a reflection of the "disease" we often attribute to androgenetic alopecia. (See Figure 1.)

All young children, no matter what racial identity, start with a concave hairline shape. The midline always lies just above the crease of the furrowed brow. This concave hairline shape evolves as the hairline

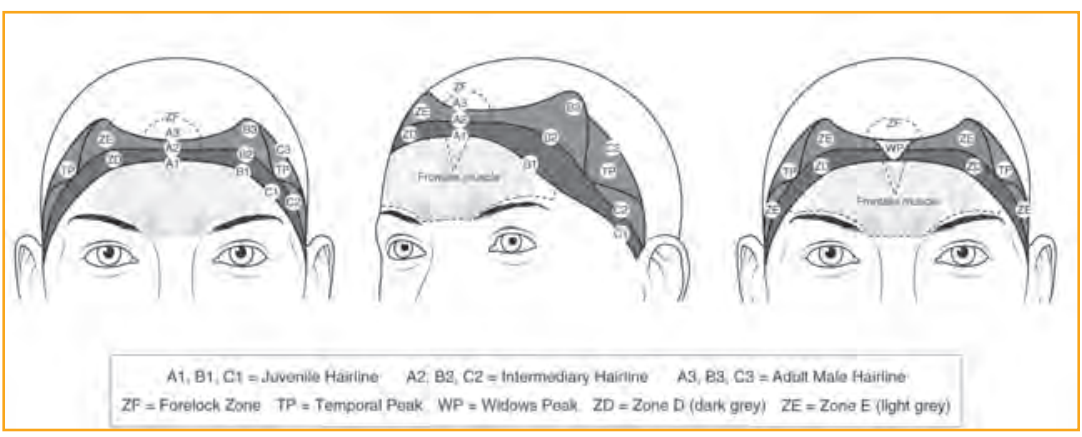

Figure 1. Hairline zones and area locations. ${ }^{4}$ recedes upward and laterally with age. At the sides of the hairline just above and in front of the ears, there are temple mounds that appear as the side hairline recedes from the smooth continuation of the leading edge of the hairline. The temple mounds are buried within the smooth continuation of the leading edge of the hairline, not showing a "mound shape" while the full concave juvenile hairline is present. In a child's hairline, there is never a widow's peak or temple peaks because the hairline is always a continuous and smooth circular shape hiding what may eventually become temple mounds, temple peaks, and a widow's peak. We studied the hairlines of 1,051 children from their annual school yearbooks to draw this conclusion. ${ }^{4}$ We also studied hundreds of boys' and girls' swim teams posted on the internet and we viewed a large number of Olympic athletes on TV at the 2012 Olympics. We extended our search to shopping malls and airports studying men and women passing by. It was clear from these randomized observations that the hairlines of men and women vary in patterns and that these patterns reflect a classic phenotype that is most certainly tied to the genetic proclivities of the anatomic hairline.

Areas such as the widow's peak and the temple peaks appear as the hairlines recede and arise from within the confines of the concave child's hairline. The shape of these peaks, when they remain, must certainly reflect a different genetic code than the surrounding areas (the hairline zone lateral to the widow's peak and the hairline zone above and below the temple peaks). For labeling purposes (see Figures 2 and 3), we have identified what we believe are the areas of interest and illustrated them. We divided the hairline into Zones $\mathrm{D}$ and $\mathrm{E}$ with distinct lines along the borders of the leading edges of these zones (A, B, and C). The widow's peak and temple peaks are found within Zones D and E. Figure 4 shows (1) a typical example of a concave hairline in a 40+-year-old female that almost certainly reflects her original hairline from childhood with some early thinning of the leading edge and (2) another 40+-year-old

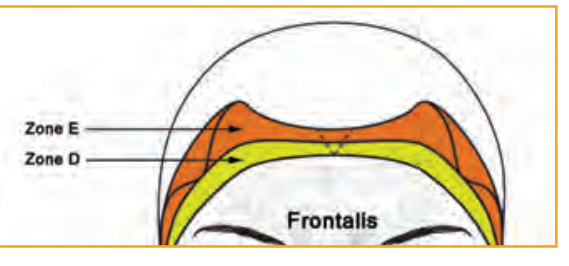

Figure 2. Hairline Zones D and E show where the temple peaks and the widow's peak will appear with aging.

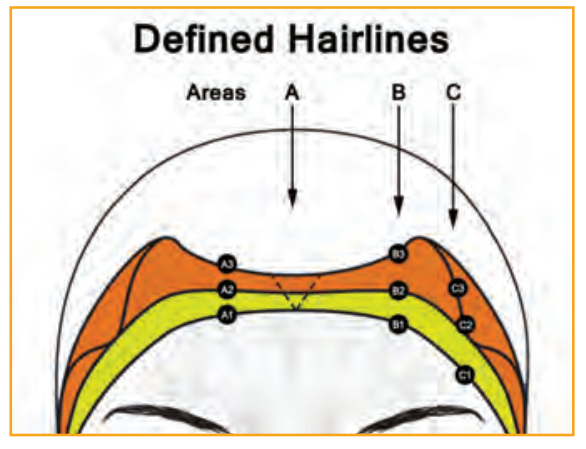

Figure 3. The hairline areas are divided into A, B, and C, and the hairlines levels are divided into 1,2 , and 3 .

$\Rightarrow$ page 203 
Hairline evolution

$\checkmark$ from front page

female with an intermediate hairline, persistent widow's peak, and prominent temple mounds.

Imagine a line directly between the child's concave hairline and the male's convex mature hairline. I will call the line between these two hairlines the "intermediate" hairline. In the midline, the distance between the child's leading concave edge of the hairline and the location of what may eventually be termed the mature hairline of the male reflect a distance of approximately $2 \mathrm{~cm}$ at the midline in the adult. These two zones can be divided into a superior zone of
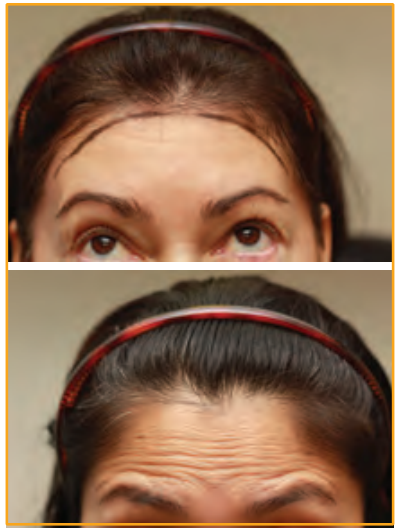

Figure 4. Two 40+-year-old females, one with a persistent concave hairline and one with unusually prominent temple mounds and widow's peak, with an intermediate hairline.

about $1 \mathrm{~cm}$ in height (Zone E) and an inferior zone approximately $1 \mathrm{~cm}$ in height (Zone D) as well. As the widow's peak lies in these zones (Figure 5), the widow's peak can never exceed the height of these two zones $(\sim 2 \mathrm{~cm})$. If the height of the widow's peak is less than $2 \mathrm{~cm}$ in length, the broad base part of it always exists in Zone $E$ and the inferior narrow point may extend inferiorly into Zone E alone, or Zone D and E, which would make it larger and more prominent visually. The temple peaks emerge from the concave juvenile hairline and, when they are present, they are always in Zone E and sometimes extend to Zone D.

For labeling purposes, we have defined three hairlines in Figure 5: (1) the juvenile hairline (which is found in all children at

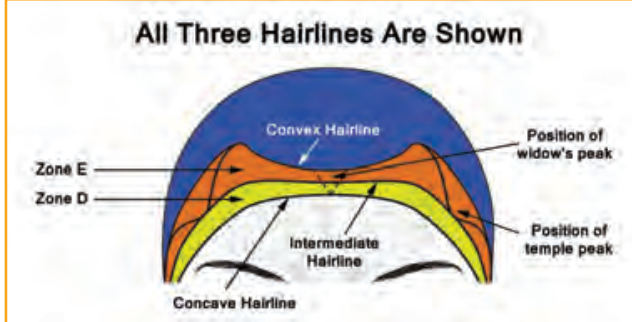

Figure 5. Three hairlines are shown (concave, intermediate, and convex). Note the position of where the widow's peak and temple peaks would be found, when present.

some point early in their development), which borders the highest crease of the furrowed brow and should be called the concave hairline, (2) the convex hairline (often called a mature male hairline in men with its highest point located superior to the lateral orbital rim), and (3) an intermediate hairline (a hairline midway between the convex and concave hairlines, directly between Zones D and E).

We identified important areas of the hairlines medially to laterally. Along these areas, we identified points that allowed us to divide the hairlines from the medial position to the lateral position as labeled (Figure 3):

- The frontal medial area, which we will call Point A (the central point of Area A)

- The "corner" hairline, which we will call Point B (the central point of Area B). Point B is defined by a line drawn approximately and superiorly to the lateral orbital rim.

- The side hairline area in front and superior to the ears (the mound area), which we call Point $C$ (the central point in Area C). The mounds emerge from the lateral migration of Point $\mathrm{C} 1$ in Area $\mathrm{C}$ and the superior migration of Point B1 in Area B.
The widow's peak is always found directly in the middle of Area A at Point A, and it emerges as Zone D (and occasionally Zone $\mathrm{E}$ ) recede. The mature male hairline is convex in shape. The highest point of the mature hairline's convexity is found in Area $\mathrm{B}$, and it is the most superior point of the convex shaped hairline. The place where the temple mounds originally existed on the side of the hairline (in front and superior to the ears) is in Area C.

If this is put together with the numbered hairlines, the central area (depending where the hairline is located with respect to the juvenile hairline) goes from A1, which may recede upward to A2, reflecting the intermediate hairline, which has a flat frontal shape rather than a concave one. The actual locations of the hairlines (inferiorly to superiorly) have been labeled Points 1, 2, and 3 in Areas A, B, and C, where Points A1, A2, and A3 range from the midline of the concave hairline to the lowest most medial point of the convex hairline. Points $\mathrm{C} 1, \mathrm{C} 2$, and $\mathrm{C} 3$ are the most lateral points of the side hairline. When Areas A, B, and $\mathrm{C}$ are combined with Points 1, 2, and 3, we can precisely identify the position on a hairline in its various iterations. Point A1 is the midline of the juvenile hairline location at the crease of the furrowed brow. Point A2 is the midline location of the intermediate hairline and Point A3 is the lowest midline position of the mature vertex hairline that we often refer to as the mature male hairline $(\sim 2 \mathrm{~cm}$ from Point A1). Although the nomenclature referencing the "mature male hairline" is somewhat standard for our industry and does not account descriptively for females, the authors recognize it is a poor choice of terms, so we prefer the term convex hairline, which is a unisex description.

The authors believe that Zones D and E are independently genetically coded from the areas where Norwood and Ludwig focused their attention. We have much evidence for this. Women with androgenetic alopecia and thinning of the front, top, and crown area of the head often do not show thinning in Zones D and/ or E. On rare occasions, we see the persistence of Zones D and E in men who have significant patterned loss, particularly noticeable when the patient shows a Norwood Class VII pattern. We have seen men use a comb-back very effectively with persistent Zones D and E, even with a complete Norwood Class VII balding pattern. The temple peaks, which are located in Zone E, extend to Zone D some of the time. They may persist through the life of the individual and can appear quite prominent, even when there is advanced balding present in the male or female. The persistence of the temple peaks in the face of advanced balding patterns strongly suggests different genetics to the hair behind the hairline.

The forelock may be incorporated into the frontal area where the balding patterns extend inferiorly, but, frequently, they do not disappear in the defined Norwood patterns. There are many people who retain their forelock, even with frontal balding. These persistent forelocks vary in size and can be as small as an inch in diameter with an oval shape to as large a section that almost reaches the lateral fringe area in the front of the scalp and extends from Point A1 back as far as $10 \mathrm{~cm}$ or more from the leading frontal hairline edge (Figure 6). These forelocks may incorporate the widow's peak and, when they do,

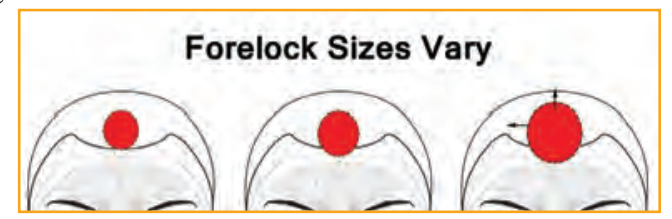

Figure 6. Forelock sizes vary inferiorly, laterally, and superiorly.

$\Rightarrow$ page 204 
Hairline evolution

$\checkmark$ from page 203

the peak defines the lowest point of the forelocks, which often exptend posteriorly into Zones D and E. Forelocks are particularly important from an artistic point of view because, if they are large enough, they create a good frame to the face. In the 1980s, Dr. Manny Merritt would create isolated frontal forelocks with a large number of smaller grafts (500 or so) as a substitute for a full frontal hair transplant reconstruction, and the results looked very good for the 1980s. Frontal forelocks run in families, and, if they persist until the male patient reaches $\sim 35$ years of age, the forelock will likely remain into old age despite progressive balding throughout the frontal area. When you see such patients, ask them who in their family have a frontal forelock and you will often find that these forelocks were present in the fathers and/or grandfathers even when advanced balding was present.

Hair direction at the hairline changes by zone. In Zone D, the hairs often point acutely downward and laterally in almost the same direction as seen in the side hairs of the temple mounds. In Zone $\mathrm{E}$, there is a transition of hair direction from the downward and lateral pointing hairs found in Zone $\mathrm{D}$ to a progressively more medial and forward pointing direction of hairs in the upper part of Zone $\mathrm{E}$ (not shown).

In Figure 7 (the official government picture of Paul Ryan), the direction of the hairs at the A2 hairline retain much of the direction dictated by Zone $\mathrm{D}$ in his intermediate hairline. The widow's peak remains strong and points slightly to the right. If Mr. Ryan would recede further upward with the formation of

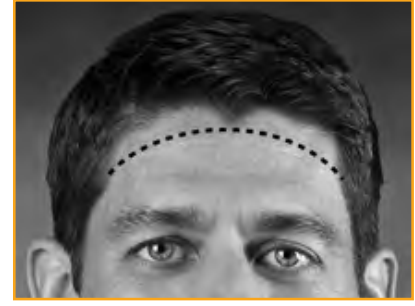

Figure 7. Intermediate hairline of former vice presidential candidate Paul Ryan shows the direction of hair growth. a convex hairline, the direction of the hairs would most likely point forward and parallel to the horizon. The hair direction in Zone $\mathrm{E}$ therefore transitions from the more lateral and downward directions found in Zone $\mathrm{D}$ to the mature hairline location (pointing forward and parallel to the horizon) that run from position A3 laterally about $5 \mathrm{~cm}$ on either side. At Point B3 of a convex hairline, the hair direction quickly shifts laterally in a transition zone of about $1 \mathrm{~cm}$ wide where we would see the formation of a "part" that makes the hair fall to the side and layer laterally. Look carefully at women who retain their concave hairlines and you may see the whole story on hair direction in the hairline on just one woman's head if you examine hair directions in Zones D and E (see Figure 4).

In a study of 360 women, Nusbaum reported $83 \%$ have a widow's peak by the age of $40 .{ }^{3}$ That means that $83 \%$ of women have lost hairs in Zone D and possibly in Zone E. Hairline reconstruction with hair transplants or hairline lowering procedures often address hairlines that have receded to Points A3 and B3, or in women who have had a very high hairline in Areas A and B since childhood, where Point A1 may still hug the lowest crease of the furrowed brow. In the latter group, I am sure that when these women were very young (e.g., 5-7 years old) they probably would have shown that the highest crease of the furrowed brow was unusually high. They will almost always give a history of a high hairline since childhood, and the surgeon will often elicit a family history of a high hairline in these instances. We see females complain that they are balding at Point B3 and want that area filled in with hair transplants. Balding at Point B3 is fairly common in women as they age and even more common in women who had brow lifts and face lifts.

Rather than show example after example of variations in hairline presentations, be assured that mix and match combination of hairline "point locations" can reflect some combination of A1-3, B1-3, and C1-3, and the variations in the appearance of a hairline can vary widely. Hairline recession to Point C3, for example, may not conform to Point B3 on the same person.

To exemplify these zones, lines, and points, we have used two pictures of public figures, which are easily accessible from public sources, as well as pictures of non-public figures. We have taken the liberty to draw the concave hairline into some of these pictures to help you understand the changes in the appearance of these hairlines since childhood.

Figure 8 shows in intermediate hairline in former vice presidential candidate Paul Ryan and is compared to the hairline of a young woman who also has an upward eroding interme-

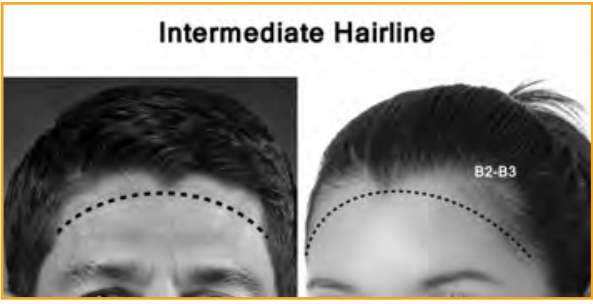

Figure 8. Intermediate hairline of Mr. Ryan (left) and unidentified female (right). The female is undergoing thinning toward a convex hairline and Mr. Ryan shows an emerging intermediate hairline. diate hairline. The juvenile hairlines have been drawn in by the authors. The female (photo on the right) is actually undergoing a transitional balding process with thinning to Areas B3 and the superior part of $\mathrm{C} 3$. In both pictures, a subtle suggestion of a temple peak can be seen emerging from the temple mounds in the lateral hairline in area C. Mr. Ryan has not evolved temple peaks.

Figure 9 shows a patient before and after a transplanted intermediate hairline. She wanted to bring back her juvenile concave hairline and Dr. Jino Kim accommodated her request. Note the direction of the hairs in the after picture, which reflects a normal hair direction for Zone D.

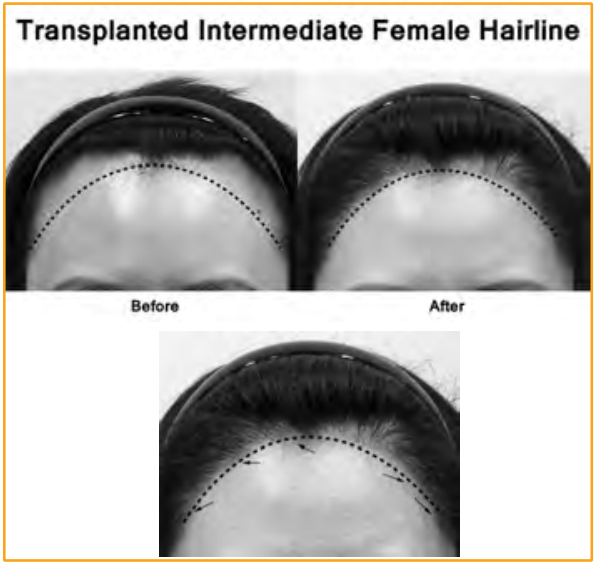

Figure 9. Surgical restoration of a concave hairline from a patient who did not like her intermediate hairline (top) (before and after photographs). Hair direction shown with arrows (bottom)

Figure 10 shows former president Clinton's present hairline. Pictures available in archives show a complete concave juvenile hairline when he was governor and during his early presidential years. There are many pictures that show off the highest crease of his furrowed brow during emotional moments,

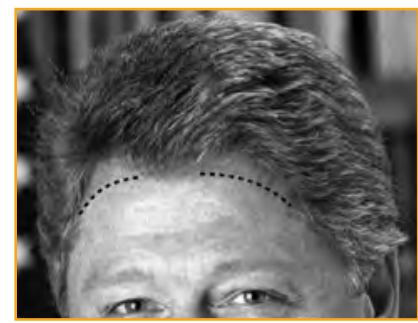

Figure 10. Former president Bill Clinton shows hairline characteristics defined in text. which is exactly where we drew in his concave juvenile hairline on 
the figure. His present hairline is changing and he has retained what appears to be a weak widow's peak. Zone D seems to be receding at the sides of the widow's peak in the hairline area. Point B1 is receding to Point B2. His temple mounds are evident but still intact, but their early appearance indicates that Point B2 is transitioning upward along with the upper part of Point C1. Mr. Clinton shows that hairlines continue to evolve as we age.

\section{References}

1. Norwood, O.T., and R.C. Shiell. Hair Transplantation Surgery, 2nd Edition. Springfield (IL): Charles C. Thomas, 1984; pp. 5-10.

2. Ludwig, E. Classification of the types of androgenetic alopecia (common baldness) occurring in the female sex. $\mathrm{Br} \mathrm{J}$ Dermatol. 1977; 97:247-247.

3. Nusbaum, B.P., and S. Fuentefria. Naturally occurring female hairline patterns. Dermatol Surg. 2009; 35:907-913.

4. Rassman, W.R., J.P. Pak, and J. Kim. Phenotype of Normal Hairline Maturation. Facial Plastic Surgical Clinics of North America. Published by Elsevier Inc., August 2013.
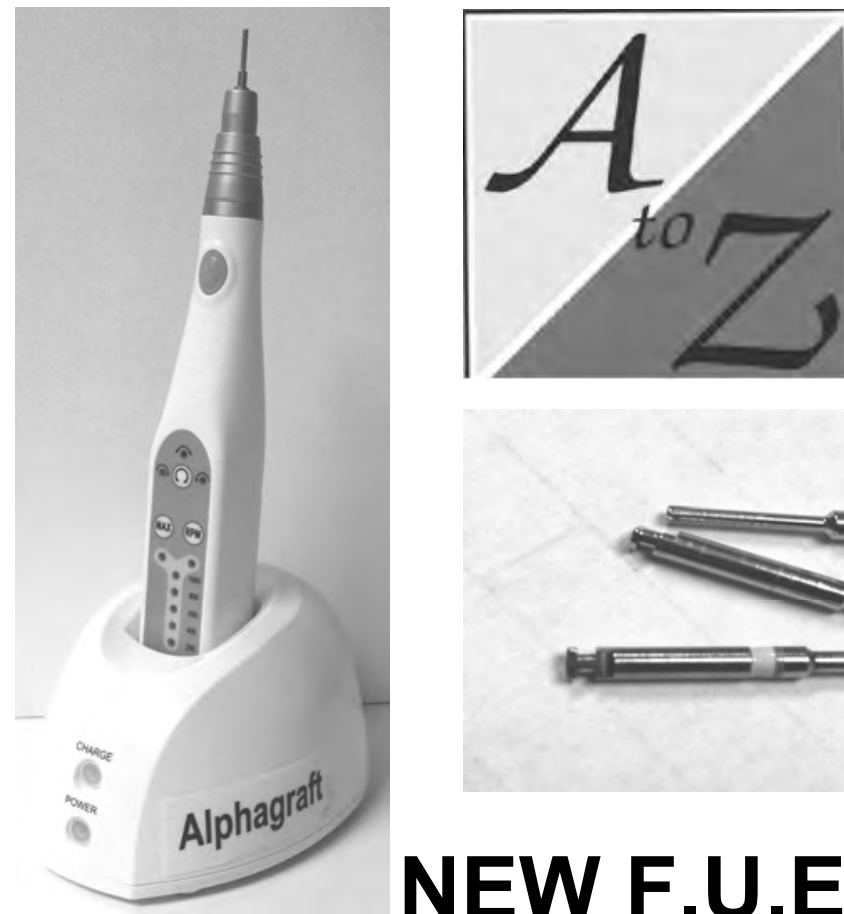

\section{Kenny Moriarty}

Vice President

Cell: 516.849 .3936

Kenny@georgetiemann.com

www.atozsurgical.com

\section{LED attachment} now available!

\section{NEW F.U.E. DEVICE}

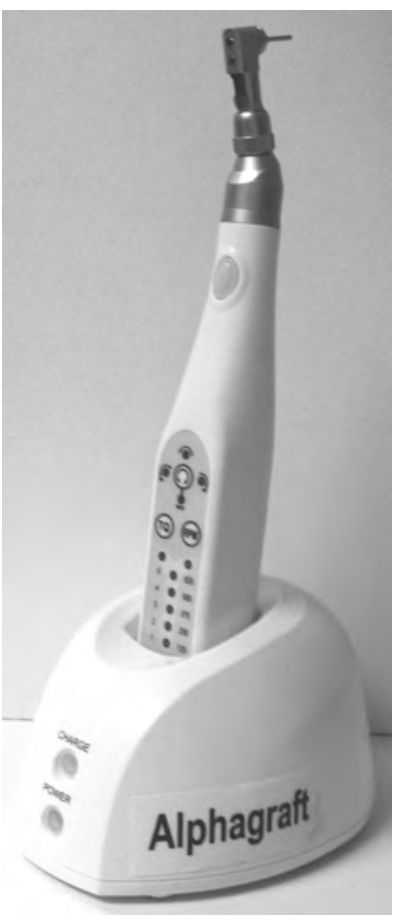

A to $Z$ is now offering Mini Alphagraft with contra angled or straight angle; with more torque. Don't miss out call Alphagraft Hair Implant Inc. or A-Z Surgical today! Ask about FREE punches with your purchase.

\section{www.atozsurgical.com}

